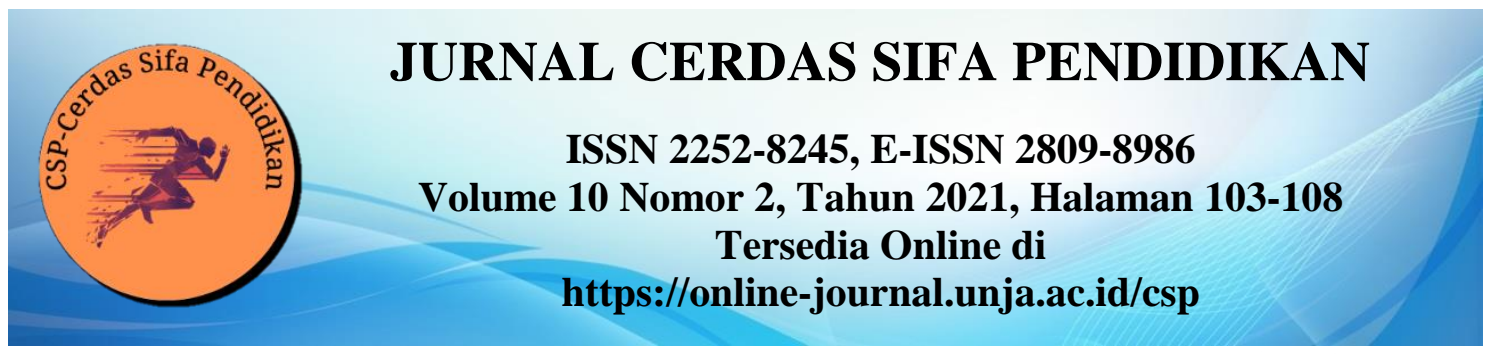

Research Article

OPEN ACCESS

\title{
Pelatihan Model Pendekatan Pembelajaran Teaching Games for Understanding (TGfU) Untuk Atlet Anggar Jambi
}

\author{
Grafitte Decheline $^{1}$, Fitri Diana ${ }^{2}$, Sugih Suhartini ${ }^{3}$, Ade Setiowati ${ }^{4}$ \\ Kepelatihan Olahraga, FKIP, Universitas Jambi. Indonesia ${ }^{1}$ \\ Pendidikan Olahraga dan Kesehatan, FKIP, Universitas Jambi. Indonesia ${ }^{2,3,4}$ \\ Correspondence Author : grafiti@unja.ac.id
}

\begin{abstract}
ABSTRAK
Teaching Games for Understanding (TGfU) merupakan sebuah model pendekatan yang telah diterapkan di Negara-negara Maju sebagai salah satu sistem pendidikan Jasmani disana. Perkembangan model pendekatan ini di Indonesia belum dapat dikategorikan sebagai model yang membanggakan. Penerapan model pendekatan ini masih sangat minim khusunya di Indonesia. Model Pendekatan TGfU bukan hanya dapat diterapkan di sekolah sebagai permainan pengantar dalam pembelajaran, namun juga digunakan untuk pengantar dalam pelatihan untuk atlet di berbagai cabang olahraga. Hasil dari pelatihan ini adalah antusiasme dari atlet yang mengikuti kegiatan ini. Kegiatan Pelatihan Model Pendekatan TGfU untuk atlet anggar sangat diterima oleh para atlet. Selain itu, Model Pendekatan TGfU masih belum dikenal secara luas baik oleh atlet, guru maupun pelatih, sehingga masih diperlukan berbagai cara untuk dpaat memasalkan model pendekatan ini. Model Pendekatan TGfU dapat dijadikan sebagai salah satu alternatif dan juga modifikasi teknik dan taktik dalam berbagai cabang olaharaga. Pengabdian berhasil menemukan fakta bahwa dengan menggunakan model pendekatan Teaching Games for Understanding, atlet dapat lebih memahami dan melatih taktik dalam permainan anggar. Hal ini berdasarkan dengan pelatihan yang dilakukan selama berada di lapangan.
\end{abstract}

Kata Kunci: Anggar, Teaching Games for Understanding

\section{Training Model Learning Approach Teaching Games for Understanding (TGfU) for Jambi Fencing Athletes}

\author{
ABSTRACT \\ Teaching Games for Understanding (TGfU) is a model approach that is applied \\ in developed countries as one of the physical education systems there. The development
}


of this approach model in Indonesia cannot be categorized as a proud model. The application of this approach model is still very minimal, especially in Indonesia. The TGfU Approach Model can not only be applied in schools as an introduction to learning, but also used as an introduction to training for athletes in various sports. The result of this training is the enthusiasm of the athletes who take part in this activity. The TGfU Approach Model Training activity for fencing athletes was very well received by the athletes. In addition, the TGfU Approach Model is still not widely known by athletes, teachers and coaches, so that various ways are still needed to formulate this approach model. The TGfU Approach Model can be used as an alternative and also a modification of techniques and tactics in various sports. Devotion succeeded in finding the fact that by using the Teaching Games for Understanding approach model, athletes could better understand and practice tactics in the game of fencing. This is based on the training carried out while in the field.

Keyword: Anggar, Teaching Games for Understanding,

\section{PENDAHULUAN}

Teaching Games for Understanding (TGfU) merupakan pembelajaran yang didasarkan pada tingkatan permainan yang sesuai dengan perkembangan dan aktivitas pembelajaran permainan modifikasi yang berpusat pada masalah-masalah taktik dan para siswa memecahkannya. Pendekatan pembelajaran pendidikan jasmani untuk memperkenalkan pengertian Olahraga kepada siswa untuk bermain.

Pengembangan taktik lebih diperlukan dari pada pengembangan teknik dalam pembelajaran Pendidikan Jasmani di Sekolah. Karena sesuai dengan tujuan pembelajaran Pendidikan Jasmani di Sekolah yaitu memberikan pengetahuan kepada siswa tentang Pendidikan Jasmani dan Olahraga sebagai dasar pengembangan motorik siswa.

Pendekatan ini merupakan model pendekatan yang baru yang akan diterapkan di sekolah. Sebagai sesuatu yang baru itulah perlu adanya masa transisi dan percobaan terhadap sekolah baik kepada guru dan siswa di Sekolah tersebut. Model pendekatan ini diterapkan dan menjadi dasar pembelajaran di Sekolah yang diterapkan oleh Universitas atau Perguruan Tinggi sebagai pembanding dengan konsep pembelajaran yang lama yang terlalu menitikberatkan kepada teknik.

Sebenarnya model Pendekatan ini sudah diperkenalkan oleh Muska Mosston mulai tahun 1966. Namun pendekatan ini belum diterapkan oleh guru-guru Pendidikan Jasmani di Sekolah. Kebanyakan guru masih menerapkan sistem pembelajaran dan pendekatan yang bertumpu pada teknik bukan taktik. Padahal jika pembelajaran menitikberatkan pada teknik itu artinya pembelajaran bertujuan untuk melatih bukan untuk pembelajaran sebagai transfer ilmu pengetahuan kepada siswa.

Dalam pendekatan ini, dikonseptualisasikan dari penekanan yang berpusat pada guru (Teacher-centered) sampai ke penekanan yang berpusat pada siswa (Studentcentered). Pembelajaran yang diterapkan berupa Whole-Part-Whole (keseluruhanbagian-keseluruhan) maksudnya adalah pembelajaran yang diberikan kepada siswa berupa keseluruhan materi pembelajaran yang difahami oleh siswa, kemudian adanya penekanan terhadap taktik dan teknik yang disampaikan oleh guru setelah itu kembali secara keseluruhan penggabungan dari pemahaman siswa tentang permainan dan materi taktik yang diberikan oleh guru. (Saryono, JPJI, 2009). 
Salah satu cara atau metode yang akan diujicoba kegunaannya adalah menggunakan metode Teaching Games for Understanding (TGfU). Metode ini merupakan metode taktikal approach atau pendekatan taktik dimana pelatih sebagai fasilitator memberikan pemahaman tentang taktik dalam suatu permainan, namun penyampaiannya lebih mengarah pada sebuah permainan dimana permainan yang dimaksud adalah untuk membantu pemahaman yang meningkat kepada siswa atau mahasiswa.

Pendekatan dalam permainan bertujuan memberikan pengalaman untuk atlet agar dapat mengeksplorasi segala kemungkinan yang akan terjadi di dalam permainan hingga pertandingan. Pendekatan teknik sering dilakukan oleh pelatih di hari-hari biasa latihan, namun pendekatan taktik sering dilupakan karena dirasa dapat dipelajari oleh atlet berdasarkan pengalaman dan olah kata dari pelatih.

Teaching Games for Understanding (TGfU) diharapkan dapat menajdi salah satu alternatif model pendekatan yang dapat dijadikan sebagai sarana modifikasi permainan dan latihan untuk Atlet. Seringkali atlet merasa jenuh dengan latihan teknik yang berulang dilakukan, maka pelatih boleh memberikan pendekatan ini sebagai selingan dalam rencana latihan sehingga latihan yang diberikan kepada atlet dapat sangat bervariasi tergantung pada kebutuhan atlet dan juga pelatih.

Pemberian model pendekatan ini juga merupakan salah satu solusi bagi pelatih dalam menyampaikan dan melatih taktik dalam permainan hingga pertandingan. Taktik merupakan salah satu faktor penetu dalam keberhasilan atlet meraih prestasi. Selain komponen kondisi fisik, dan teknik yang dimiliki oleh atlet, TAKTIK merupakan yang paling penting. Menggunakan taktik yang tepat dalam sebuah pertandingan dapat memberikan peluang kemenangan yang lebih besar pula. Maka dari itu, untuk membantu pelatih dalam memberikan pengalaman dan pelatihan taktik kepada atlet, model pendekatan Teaching Games For Understanding ini hadir untuk memenuhi kebutuh tersebut.

\section{METODE}

Kegiatan pengabdian pada masyarakat ini akan dikemas dalam bentuk Pelatihan. Dalam penyampaian berbagai materi kegiatan, akan dilakukan dengan cara sebagai berikut: pertama disampaikan ceramah, kemudian dilanjutkan dengan pelaksanaan pengenalan model pendekatan TGfU.

Kegiatan pengabdian pada masyarakat ini dilakukan dengan tahapan sebagai berikut:

a. Tahap awal, yaitu dilaksanakannya observasi ke lokasi pengabdian, pertemuan dengan Pelatih Cabang Olahraga Permainan mengenai pelatihan Model pendekatan .

b. Tahap kedua, adalah pelatihan mengenai model pendekatan Teaching Game for Understanding.

c. Evaluasi untuk mengidentifikasi kekurangan dan kelebihan dalam pelaksanaan kegiatan kali ini, sehingga dapat dijadikan masukan pada kegiatan berikutnya. Setelah itu dilakukan penyusunan laporan dan proses administrasi penyampaian laporan kegiatan pada Lembaga Pengabdian Pada Masyarakat Universitas Jambi.

Adapun langkah-langkah kegiatan yang dilakukan pada kegiatan ini adalah :

a. Menyampaikan izin kepada Pelatih Cabang Olahraga Permainan dengan ditandai dengan penandatangan mitra untuk melakukan kegiatan penyuluhan.

b. Mendata jumlah peserta yang mengikuti kegiatan penyuluhan. 
c. Melakukan sosialisasi berupa penyampaian materi terkait Model Pendekatan Teaching Game for Understanding

Dalam pelaksanaan ini ada satu mitra yang terlibat di dalamnya yaitu Pelatih dan Atlet dalam Cabang Olahraga Anggar. Pihak mitra sebagai peserta dan merupakan sasaran penyuluhan. Pengurus mengkoordinasikan atletnya untuk mengikuti kegiatan penyuluhan.

\section{HASIL DAN PEMBAHASAN}

Agar pelaksanaan kegiatan pengabdian berjalan dengan lancar, maka dilakukan langkah pendahuluan sebagai berikut:

a. Tahap perencanaan

Pada tahap ini dilakukan penyususnan proposal, pembuatan materi serta pembagian tugas kerja tim pengabdian

b. Tahap Pendekatan

Pada tahap ini diitentukan langkah-langkah kerja sebagai berikut:

1. Melakukan observasi ke IKASI Provinsi Jambi untuk melakukan Pelatihan

Pendekatan Teaching Games for Understanding kepada atlet Anggar di IKASI

Prov. Jambi.

2. Memberikan proposal Pelatihan Pendekatan TGfU,

3. Memastikan bahwa atlet dapat mengikuti kegiatan Pelatihan

4. Menetukan waktu kegiatan melakukan Pelatihan Pendekatan Teaching Games for Understanding kepada atlet Anggar di IKASI Prov. Jambi .

c. Tahap Pelaksanaan

Permainan yang dimodifikasi adalah permainan sederhana yang dapat dilakukan oleh Atlet sesuai dengan komposisi, tujuan dan repetisinya. Permainan yang diberikan adalah:

1. Lempar Tangkap Bola

Tujuan dari permainan ini adalah untuk menyeimbangkan posisi tubuh, dan berada steady pada posisi bertahan dan menyerang.

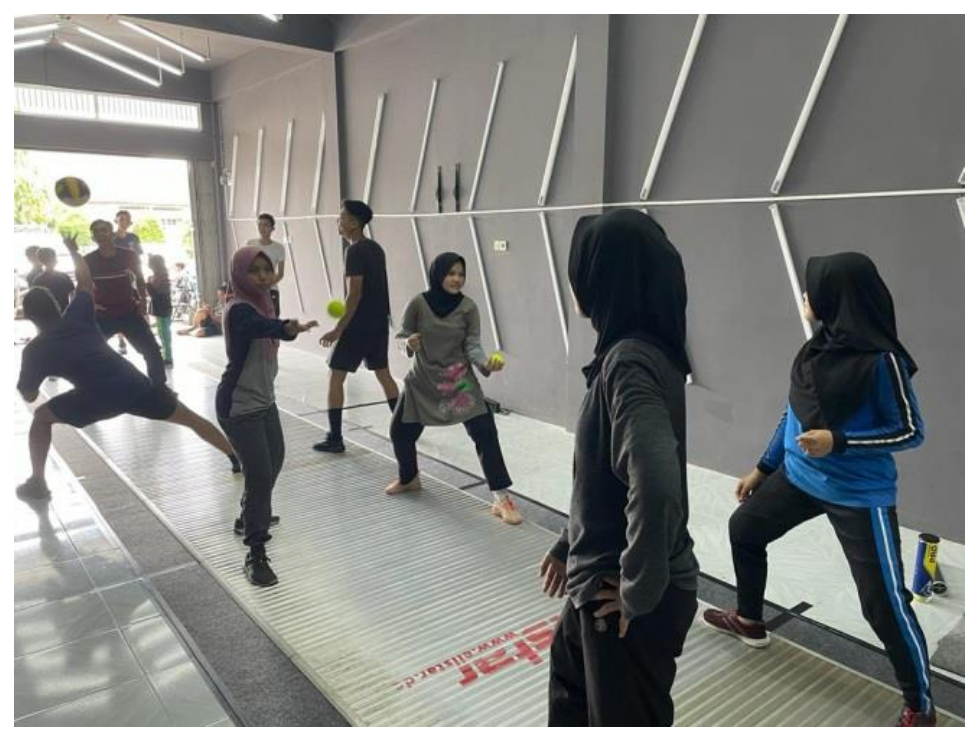

Gambar 1. Permainan Lempar Tangkap Bola 
2. Permainan Pass Volley

Tujuan dari permainan ini adalah untuk mencuri bola dari lawan tapi tetap dalam keadaan posisi on-guard.

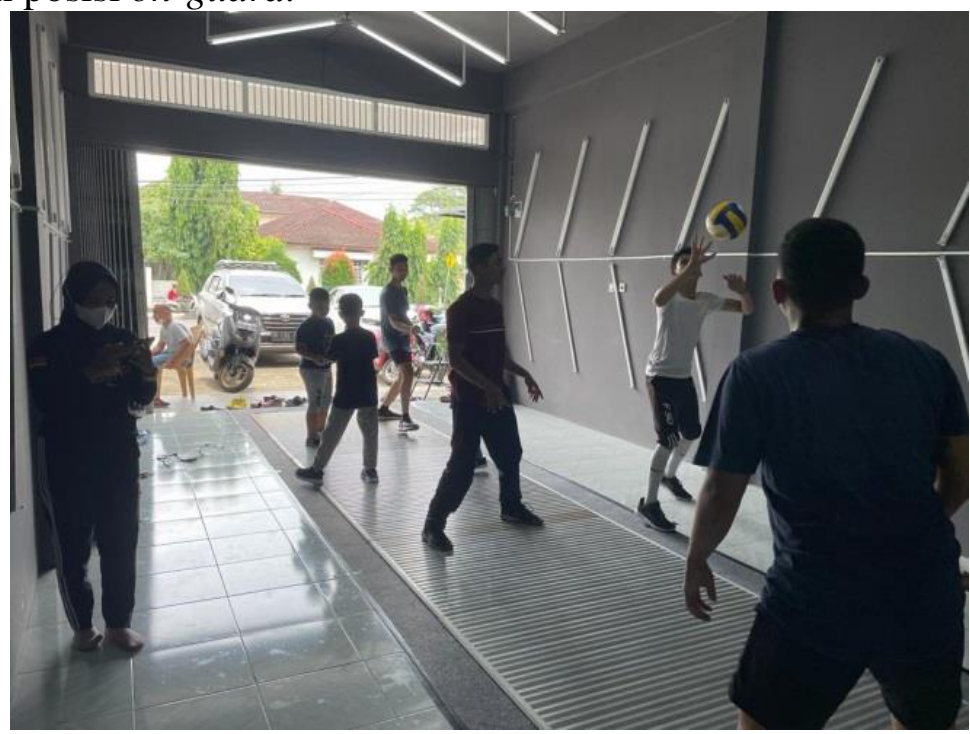

Gambar 2. Permainan Pass Volley

3. Permainan Steady Attack

Tujuan dari permainan ini adalah untuk mestabilkan tubuh atlet. Saat menerima dorongan atlet tetap dalam keadaan stabil. Gunanya adalah pada saat pertandingan, kaki memiliki kekuatan yang cukup untuk menopang badan dan tidak gampang terjatuh.

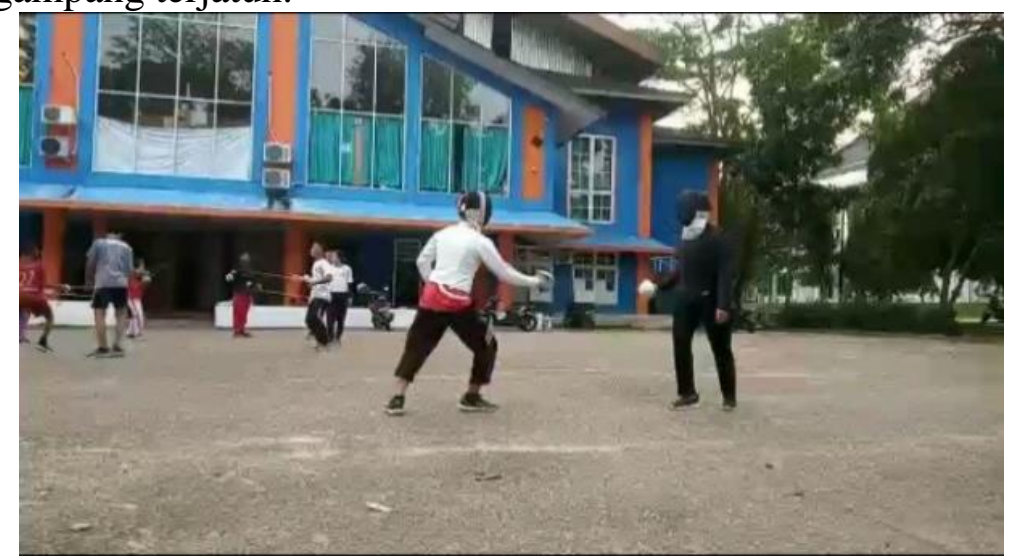

Gambar 3. Permainan Steady Attack

Para peserta yang dalam pengabdian ini adalah atlet Anggar di IKASI Jambi. Peseta dalam kegiatan sosialisasi memberikan beberapa tanggapan terhadap kegiatan yang diberikan. Berikut adalah tanggapan peserta dalam kegiatan Penyuluhan:

1. Dengan "Pelatihan Model Pendekatan TGfU untuk atlet anggar" para peserta memahami namun masih belum terlalu mengenal tentang penerapan model pendekatan ini.

2. Melalui "Pelatihan Model Pendekatan TGfU untuk atlet anggar" diharapkan peserta dapat menerapkan model penedekatan dalam meningkatan kemampuan teknik dengan baik. 
3. Melalui "Pelatihan Model Pendekatan TGfU untuk atlet anggar " diharapkan peserta semakin memacu dirinya untuk dapat melakukan kegiatan olahraga dalam kesehariannya..

Kegiatan " Pelatihan Model Pendekatan TGfU untuk atlet anggar" sebaiknya sering dilakukan sebagai kebiasaan agar peserta dapat memiliki berbagai pendekatan dan modifikasi dalam pelatihan dan latihan yang mereka lakukan di cabang olahraga Anggar. Model pendekatan ini sebagai salah satu alternatif agar latihan tidak terasa membosankan namun latihan tetap sesuai dengan tujuan baik untuk melatik teknik maupun taktik dalam permainan.

Dari kegiatan Pelatihan Model Pendekatan TGfU untuk atlet anggar ini sebagai salah satu sarana kegiatan yang tidak menjenuhkan dan dapat dijadikan sebagai aktivitas refreshing untuk para atlet, dapat ditarik kesimpulan:

1. Kegiatan Pelatihan Model Pendekatan TGfU untuk atlet anggar sangat diterima oleh para atlet

2. Model Pendekatan TGfU masih belum dikenal secara luas baik oleh atlet, guru maupun pelatih, sehingga masih diperlukan berbagai cara untuk dpaat memasalkan model pendekatan ini

3. Model Pendekatan TGfU dapat dijadikan sebagai salah satu alternatif dan juga modifikasi teknik dan taktik dalam berbagai cabang olaharaga.

\section{DAFTAR RUJUKAN}

Aliyanti, A. (2014). Upaya Meningkatkan Hasil Belajar Keterampilan Lempar Tangkap Bola Kecil Dengan Modifikasi Permainan Tradisioanal Boi. Active: Journal of Physical Education, Sport, Health and Recreation, 3(6).

Hadinata, R., \& Decheline, G. (2018). Pengembangan Model Permainan Tradisional Hitam Hijau Terhadap Kualitas Fisik Siswa Sekolah Dasar Negeri 211/Ix Muaro Jambi. Jurnal Cerdas Sifa, 1(2), 78-86.

Hoffman, S. J. (2014). Introduction to Kinesiology. In Medicine \& Science in Sports \& Exercise (Vol. 46, Issue 6). https://doi.org/10.1249/mss.0000000000000347

Husdarta. (2014). Manajememn Pendidikan Jasmani. Bandung: Alfabeta

Rachman, H. A. (2008). Teaching games for understanding (TGfU): memahami pendekatan taktik sebagai model pembelajaran dalam pendidikan jasmani. Jurnal Pendidikan Jasmani Indonesia, 5(2).

Sobarna \& Hambali. (2018). Penerapan Modifikasi Alat Bantu terhadap Minat Siswa dalam Pembelajaran Tolak Peluru. Cimahi: STKIP Pasundan 